\title{
Configuration of a Southern Ocean Storm Track
}

\author{
TOBIAS BISCHOFF AND ANDREW F. THOMPSON \\ California Institute of Technology, Pasadena, California
}

(Manuscript received 4 April 2014, in final form 12 July 2014)

\begin{abstract}
Diagnostics of ocean variability that reflect and influence local transport properties of heat and chemical species vary by an order of magnitude along the Southern Ocean's Antarctic Circumpolar Current (ACC). Topographic "hotspots" are important regions of localized transport anomalies. This study uses a primitive equation channel model to investigate the structure of eddy kinetic energy (EKE), one measure of variability, in an oceanic regime. A storm-track approach emphasizes the importance of stationary eddies, which result from flow interactions with topography, on setting EKE distributions. The influence of these interactions extends far downstream of the topography and impacts EKE patterns through localized convergence and divergence of heat. Unlike for zonal averages, local contributions to the stationary fluxes from terms that integrate to zero in a zonal average are important. The simulations show a strong sensitivity of the zonal structure as well as the distribution and amplitude of stationary eddy fluxes to the surface wind forcing. By focusing on local, time-averaged stationary eddy fluxes, insight into the dynamical structure of the ACC can be gained that is concealed in the averaging procedure associated with traditional zonal or along-stream analyses.
\end{abstract}

\section{Introduction}

The distribution of eddy kinetic energy (EKE) impacts the complex dynamical balances of momentum, heat, and tracers in the Southern Ocean. The dominant feature of the Southern Ocean EKE distribution, revealed in early altimetric data, is its enhancement around topographic "hotspots," such as Kerguelen or Campbell Plateaus (e.g., Le Traon and Morrow 2001). Consequently, eddy diffusivities, which reflect transport properties (e.g., Ferrari and Nikurashin 2010) and are required to accurately represent the Antarctic Circumpolar Current (ACC) in coarse numerical models, display strong zonal variability along the ACC. Similarities with zonal variations of EKE in the atmosphere have led to a consideration of ocean storm tracks and their role in maintaining the ACC's vorticity balance (Hughes 2005; Williams et al. 2007; Thompson and Naveira Garabato 2014).

In the atmospheric literature, storm tracks have been defined as regions of locally enhanced EKE. The existence and dynamics of these atmospheric storm tracks

Corresponding author address: Tobias Bischoff, Division of Geological and Planetary Sciences, 1200 E. California Blvd., Pasadena, CA 91125.

E-mail: tobias@caltech.edu have been linked to various forcing mechanisms that locally increase baroclinicity (e.g., Hoskins and Valdes 1990; Chang and Orlanski 1993). These forcings include zonally varying orography or patterns of surface heat flux convergence due to the presence of boundary currents. Recent studies have shown that the structure and zonal extent of atmospheric storm tracks (enhanced EKE) can partly be explained via the excitation of stationary Rossby waves (Kaspi and Schneider 2011a,b) that locally increase baroclinicity downstream of a forcing region. The length scale of atmospheric storm tracks can be inferred from the length scale of stationary atmospheric Rossby waves (e.g., Lee 1995; Swanson et al. 1997; Kaspi and Schneider 2011a,b). However, it is unclear how in an oceanic regime the presence of stationary meanders can also act to localize EKE.

Theories of residual heat, momentum, and tracer transport in the Southern Ocean rely mostly on a zonally or streamwise-averaged framework (e.g., Marshall and Radko 2006). Thus, the residual overturning streamfunction of the Southern Ocean gives an average picture of the dynamics, as it is only meaningfully defined if the boundary terms in the zonal or streamwise average of the momentum equations vanish. Observations identify significant zonal asymmetry in ACC properties (e.g., Naveira Garabato et al. 2011; Thompson and Sallée 
2012). The number of jets and fronts vary with bottom topography (Thompson et al. 2010) and the meridional transport of heat and tracers can be strongly enhanced around major topographic features (e.g., MacCready and Rhines 2001; Naveira Garabato et al. 2007). Zonally averaged theories are naturally unable to explain these observations and conceal local aspects of the dynamics within integrated quantities, and theories for zonally varying flows need to be considered. In this context, previous work has highlighted the importance of stationary eddy fluxes on the momentum balance in the context of blocked reentrant channels that are forced by constant surface wind stress (e.g., Hallberg and Gnanadesikan 2001; Tansley and Marshall 2001). Our goal is to explore variability in the meander structure and eddy characteristics in response to changes in the wind stress forcing by analyzing a set of idealized channel simulations with a long channel and consider how flow interactions with topography shape high EKE regions in an oceanic regime.

\section{Idealized simulations}

Simulations were performed with the Massachusetts Institute of Technology general circulation model (MITgcm; Marshall et al. 1997), which is used to solve the hydrostatic Boussinesq equations on a beta plane. Our model is similar to the one in Abernathey et al. (2011). Unlike Abernathey et al. (2011), we use a channel that is $8000 \mathrm{~km}$ long, $2000 \mathrm{~km}$ wide, and $3 \mathrm{~km}$ deep. The resolution is $5 \mathrm{~km}$ in the horizontal directions with 30 unevenly spaced layers in the vertical that vary from $12.5 \mathrm{~m}$ at the surface to $125 \mathrm{~m}$ at the lowest level. The Rossby radius varies between $\sim 10 \mathrm{~km}$ at the southern boundary of the domain and $\sim 30 \mathrm{~km}$ at the northern boundary. Subgrid processes are represented by a horizontal viscosity of $12 \mathrm{~m}^{2} \mathrm{~s}^{-1}$, a vertical viscosity of $3 \times$ $10^{-4} \mathrm{~m}^{2} \mathrm{~s}^{-1}$, and a vertical diffusivity of temperature of $5 \times 10^{-6} \mathrm{~m}^{2} \mathrm{~s}^{-1}$. We neglect variations of density with salinity and use a fixed thermal expansion coefficient of $\alpha=2 \times 10^{-4} \mathrm{~K}^{-1}$. The flow is subject to a Coriolis force with reference Coriolis parameter $f_{0}=-10^{-4} \mathrm{~s}^{-1}$ and gradient $\beta=10^{-11} \mathrm{~m}^{-1} \mathrm{~s}^{-1}$ as well as a gravitational acceleration of $g=9.81 \mathrm{~m} \mathrm{~s}^{-2}$. The bathymetry is given by

$$
h(x, y)=h_{0} \exp \left[-\frac{\left(x-x_{m}\right)^{2}}{2 \sigma_{x}^{2}}-\frac{\left(y-y_{m}\right)^{2}}{2 \sigma_{y}^{2}}\right] .
$$

Here, $\sigma_{x}=283 \mathrm{~km}, \sigma_{y}=141 \mathrm{~km}, x$ denotes the alongchannel coordinate, $y$ is the across-channel coordinate, $h_{0}=$ $1.5 \mathrm{~km}$ is the height of the mountain, $x_{m}$ is arbitrary because of the periodicity of the channel, and $y_{m}=1000 \mathrm{~km}$.
The flow is forced via a steady, zonally symmetric zonal surface wind stress

$$
\tau_{S}(y)=\tau_{0} \cos \left[\frac{\pi\left(y-y_{m}\right)}{L_{y}}\right],
$$

where $\tau_{0}$ is varied between 0.05 and $0.4 \mathrm{~N} \mathrm{~m}^{-2}$, and $L_{y}=$ $2000 \mathrm{~km}$ is the channel width. Bottom friction is parameterized as $\tau_{u}=\rho r_{b} \partial_{z} u$, with density $\rho=1000 \mathrm{~kg} \mathrm{~m}^{-3}$ and friction coefficient $r_{b}=1.1 \times 10^{-3} \mathrm{~m} \mathrm{~s}^{-1}$. To maintain a realistic stratification we use a $100-\mathrm{km}$-wide sponge layer at the northern boundary, where the stratification is relaxed toward an exponential profile ranging from $0^{\circ} \mathrm{C}$ at the bottom to $8^{\circ} \mathrm{C}$ at the surface with a scale height of $1 \mathrm{~km}$. The relaxation time scale decreases toward the northern boundary and has a minimum value of 7 days at $y=2000 \mathrm{~km}$ (cf. Abernathey et al. 2011).

Figure 1a shows the vertically averaged EKE at $\tau_{0}=$ $0.2 \mathrm{~N} \mathrm{~m}^{-2}$. The flow field shows a single, strong jet around and immediately in the lee of the Gaussian mountain, but breaks up into many weaker jets farther downstream (Fig. 1b). This is similar to observations in the Southern Ocean (Hughes and Ash 2001; Sokolov and Rintoul 2009). The baroclinic structure of the flow is similar to that observed in the ACC and similar to simulations in Abernathey et al. (2011), although the total transport of the flow is large [between 100 Sverdrups $\left(\mathrm{Sv} ; 1 \mathrm{~Sv} \equiv 10^{6} \mathrm{~m}^{3} \mathrm{~s}^{-1}\right)$ for $\tau_{0}=0.05 \mathrm{~N} \mathrm{~m}^{-2}$ and $900 \mathrm{~Sv}$ for $\tau_{0}=0.4 \mathrm{Nm}^{-2}$ ] because the momentum dissipation is largely accomplished by bottom friction in our simulations.

\section{Stationary meanders and heat transport}

Williams et al. (2007) link ocean storm tracks to the divergence of eddy vorticity fluxes, while Kaspi and Schneider $(2011 \mathrm{a}, \mathrm{b})$ propose that the shape of atmospheric storm tracks can be understood from the relationship between stationary eddy heat fluxes and the generation of transient EKE. In particular, the presence of a local external forcing causes stationary eddy heat fluxes to locally enhance baroclinicity. The time-mean temperature (buoyancy) flux $\overline{\mathbf{u} T}$ can be decomposed into components because of the zonal-mean fluxes, stationary eddy fluxes, and transient eddy fluxes. Using standard notation from Peixoto and Oort (1992), we have

$$
\overline{\mathbf{u} T} \equiv[\overline{\mathbf{u}}][\bar{T}]+\overline{\mathbf{u}}^{*}[\bar{T}]+[\overline{\mathbf{u}}] \bar{T}^{*}+\overline{\mathbf{u}}^{*} \bar{T}^{*}+\overline{\mathbf{u}^{\prime} T^{\prime}} .
$$

Here, the overbar $\overline{(.)}$ denotes a time average, and primes (.)' denote the associated deviations. The brackets [.] 

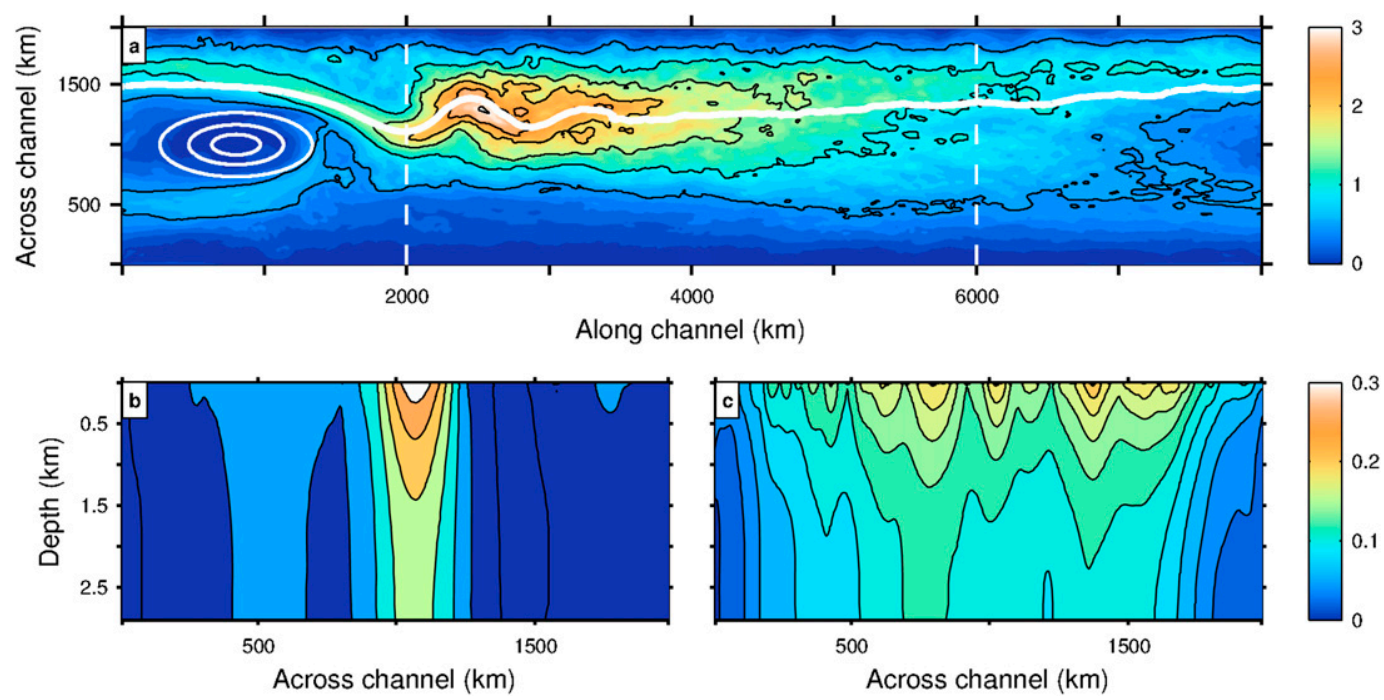

FIG. 1. (a) Vertically averaged transient $\operatorname{EKE~}\left(10^{-2} \mathrm{~m}^{2} \mathrm{~s}^{-2}\right)$ for the reference simulation at $\tau_{0}=0.2 \mathrm{~N} \mathrm{~m}^{-2}$. The white ellipses show the bathymetry at 2750,2250 , and $1750 \mathrm{~m}$; the white curve shows the $5.1^{\circ} \mathrm{C}$ surface isotherm. Time-averaged zonal velocity at (b) $x=2000 \mathrm{~km}$ and at (c) $x=6000 \mathrm{~km}$; velocities in (b) are rescaled by a factor of 2 .

denote a zonal average, and stars $(.)^{*}$ denote the deviations from the zonal average. Under the assumption of steady state (or long time mean) and a linear equation of state, the thermodynamic equation reads

$$
Q \approx \nabla \cdot\left(\langle[\overline{\mathbf{u}}][\bar{T}]\rangle+\left\langle\overline{\mathbf{u}^{\prime} T^{\prime}}\right\rangle+\left\langle\overline{\mathbf{u}}^{\dagger} \bar{T}^{\dagger}\right\rangle\right),
$$

where the divergence of the standing component is given by

$$
\boldsymbol{\nabla} \cdot\left\langle\overline{\mathbf{u}}^{\dagger} \bar{T}^{\dagger}\right\rangle \equiv \nabla \cdot\left(\left\langle\overline{\mathbf{u}}^{*}[\bar{T}]\right\rangle+\left\langle[\overline{\mathbf{u}}] \bar{T}^{*}\right\rangle+\left\langle\overline{\mathbf{u}}^{*} \bar{T}^{*}\right\rangle\right) .
$$

Here, $Q$ denotes all possible forms of diabatic heating, and $\langle$.$\rangle denotes the vertical mass-weighted integral.$ When averaging Eq. (4) zonally along the channel, one recovers that in a time- and zonal-mean framework the heat flux divergence is composed of the divergences of mean fluxes, stationary eddy fluxes, and transient eddy fluxes. Yet, locally, the transport of the zonal-mean temperature field by the stationary meandering component of the flow $\overline{\mathbf{u}}^{*}[\bar{T}]$ and the transport of the meandering component of the temperature field by the zonal-mean flow $[\overline{\mathbf{u}}] \bar{T}^{*}$ are significant. Locally, all three components of $\left\langle\overline{\mathbf{u}}^{\dagger} \bar{T}^{\dagger}\right\rangle$ in Eq. (5) can be significant, although over much of the channel, albeit not everywhere, the divergence of the stationary flux can be approximated by the sum of the two components that vanish in the zonal mean, for example, $\nabla \cdot\left(\left\langle\overline{\mathbf{u}}^{*}[\bar{T}]\right\rangle+\left\langle[\overline{\mathbf{u}}] \bar{T}^{*}\right\rangle\right)$. This is characteristic of a linear wave.

Figure 2 emphasizes the local character of the stationary fluxes by considering regional anomalies of the stationary energy flux divergence $\mathcal{D} \equiv \rho c_{p} \nabla \cdot\left\langle\overline{\mathbf{u}}^{\dagger} \bar{T}^{\dagger}\right\rangle$ over the first and second halves of the domain:

$$
\begin{aligned}
& \mathcal{D}_{1}=[\mathcal{D}]_{1}-[\mathcal{D}], \quad \mathcal{D}_{2}=[\mathcal{D}]_{2}-[\mathcal{D}] \\
& {[\cdot]_{1} \equiv \frac{1}{L_{x} / 2} \int_{0}^{L_{x} / 2} \cdot d x, \quad[\cdot]_{2} \equiv \frac{1}{L_{x} / 2} \int_{L_{x} / 2}^{L_{x}} \cdot d x .}
\end{aligned}
$$

Here, $\rho$ and $c_{p}$ are the density and the heat capacity of seawater. Dividing the channel into two halves is arbitrary, but simplifies the analysis compared to a dynamically determined separation boundary and makes the comparison among experiments easier. Focusing on anomalies is practical because the stationary eddy flux divergence anomalies and the transient eddy flux divergence anomalies, by definition, must approximately sum to zero over the first and second half of the channel. The anomalous stationary energy flux divergence around and in the lee of the mountain (first half of channel) acts, on average, to steepen the isopycnals compared to the channel-averaged stratification; that is, the associated anomalous fluxes are up the mean gradient, while downstream of the mountain (second half) it acts to relax isopycnals compared to the channel average. The steepening effect of stationary eddies over the first half of the channel is counteracted by a relaxation effect due to the transient eddies as expected from transient eddies generated by baroclinic instability that acts to relax isopycnals. This is reflected in both the flux divergences (Figs. 2a,b) and the stratification (Figs. 2c,d). It is the component of the stationary flux $\nabla \cdot\left(\left\langle\overline{\mathbf{u}}^{*}[\bar{T}]\right\rangle+\left\langle[\overline{\mathbf{u}}] \bar{T}^{*}\right\rangle\right)$ 

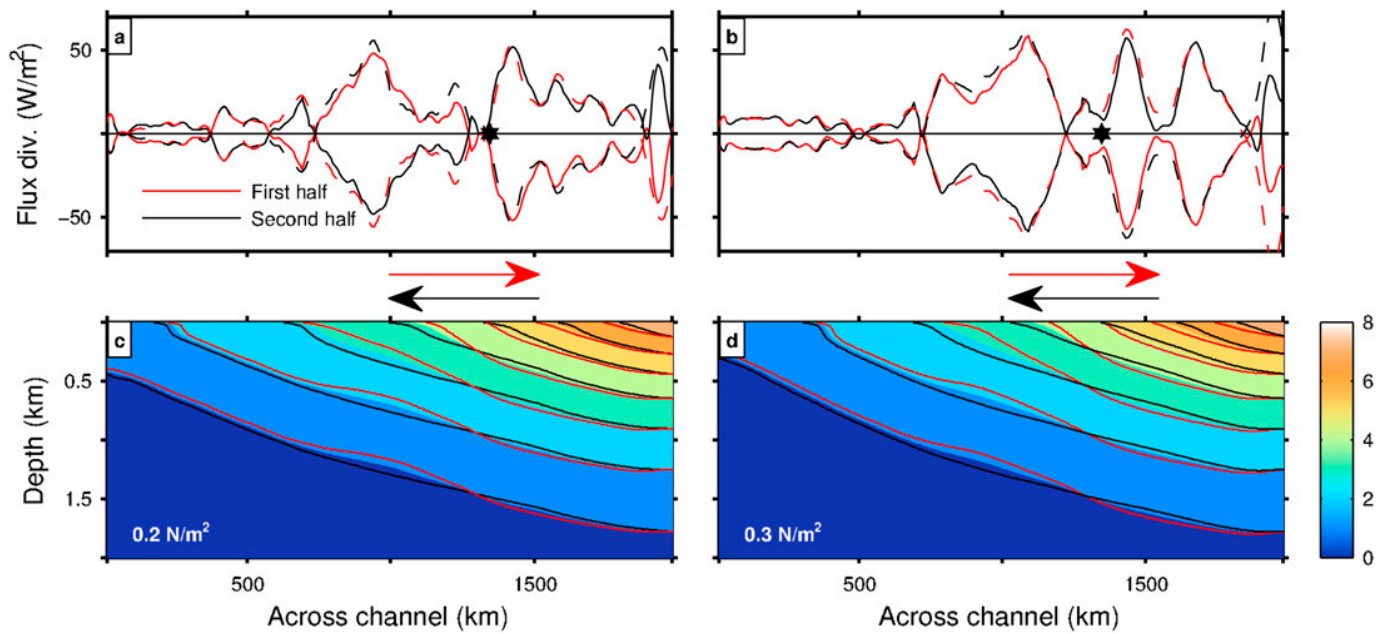

FIG. 2. (a),(b) Stationary (solid lines) and transient (dashed lines) flux divergence anomalies, defined in Eqs. (6) and (7), over the first $\left(0<x<L_{x} / 2\right.$, red curves) and second $\left(L_{x} / 2<x<L_{x}\right.$, black curves) halves of the channel. The star indicates the zonal-mean position of the $5.1^{\circ} \mathrm{C}$ isotherm. Positive (negative) values indicate cooling (heating). (c),(d) The zonal-mean temperature field (colors) and temperature contours averaged over the first (red curves) and second (black curves) halves of the domain. Panels (a),(b) and (c),(d) are for a simulation with $\tau_{0}=0.2 \mathrm{~N} \mathrm{~m}^{-2}$ and $\tau_{0}=0.3 \mathrm{~N} \mathrm{~m}^{-2}$, respectively. The arrows are indicating the direction of the anomalous heat flux due to the presence of stationary eddies in the two channel regions.

that integrates to zero over the entire domain that largely contributes to the local flux divergence and to changes in stratification along the channel. However, the nonlinear term $\boldsymbol{\nabla} \cdot\left\langle\overline{\mathbf{u}}^{*} \bar{T}^{*}\right\rangle$ is important and cannot be neglected.

The amplitude of surface westerlies over the Southern Ocean has increased during the past few decades (Thompson and Solomon 2002). To explore how elevated EKE regions in the ACC may respond to these changes, we consider the equilibrated response of our model to a range of wind stress amplitudes, $0.05 \mathrm{~N} \mathrm{~m}^{-2} \leq$ $\tau_{0} \leq 0.4 \mathrm{~N} \mathrm{~m}^{-2}$, with a wide range of bottom flow speeds. We define the storm track as a deviation from the zonally averaged EKE distribution. The equilibrated EKE of simulations with flat bottom topography are provided for reference (Fig. 3, dashed line). The ability of the stationary eddy fluxes to tilt isopycnals locally is diagnosed from the average stationary eddy temperature flux divergence found north and south of the temperature contour $T_{c}=5.1^{\circ} \mathrm{C}$ and then taking the difference between the northern and the southern average:

$S=\frac{1}{2} \rho c_{p}\left(\left\{\boldsymbol{\nabla} \cdot\left\langle\overline{\mathbf{u}}^{\dagger} \bar{T}^{\dagger}\right\rangle\right\}_{y\left(x, T_{c}\right)}^{L_{y}}-\left\{\boldsymbol{\nabla} \cdot\left\langle\overline{\mathbf{u}}^{\dagger} \bar{T}^{\dagger}\right\rangle\right\}_{0}^{y\left(x, T_{c}\right)}\right)$.

Here, braces $\{$.$\} denote an area-weighted integral; S<0$ $(S>0)$ implies a tendency for the standing eddies to steepen (relax) isopycnals because of the associated cross-frontal eddy heat transports.
Figure 3 shows zonal variations in depth- and crosschannel-averaged EKE (blue curves) and $S$ (red curves) as a function of $\tau_{0}$. The zonal extent of the storm track increases as the wind stress increases. The region where $S<0$ also increases, but the spatial separation between the maximum amplitudes in $S$ and EKE grows with increasing wind stress. This is likely due to the growing separation between regions of eddy generation and maximum eddy mixing, similar to the atmospheric case (Pierrehumbert 1984; Cai et al. 2007). At the same time, the region where $S<0$ is found farther downstream. In addition, plots of the Eady growth rates (Lindzen and Farrell 1980; Williams et al. 2007), a standard measure of baroclinicity (see Fig. 4a), show the separation between regions of largest baroclinicity and highest EKE is not collocated. The distance separating the two maxima is likely exaggerated in our simulation compared to the actual ACC because of the larger flow speeds advecting eddies in our simulations. Note that the Eady growth rate, as defined in Lindzen and Farrell (1980), can be related to the isopycnal tilt through thermal wind balance. Because local Eady growth rates measure the baroclinicity of the flow locally, they provide insight into where the flow is most likely susceptible to baroclinic instability [see, e.g., Williams et al. (2007) for an application to storm tracks].

Figure 3 shows that the dominant length scale of the meandering flow is about $O(1000) \mathrm{km}$ (gray dashed 

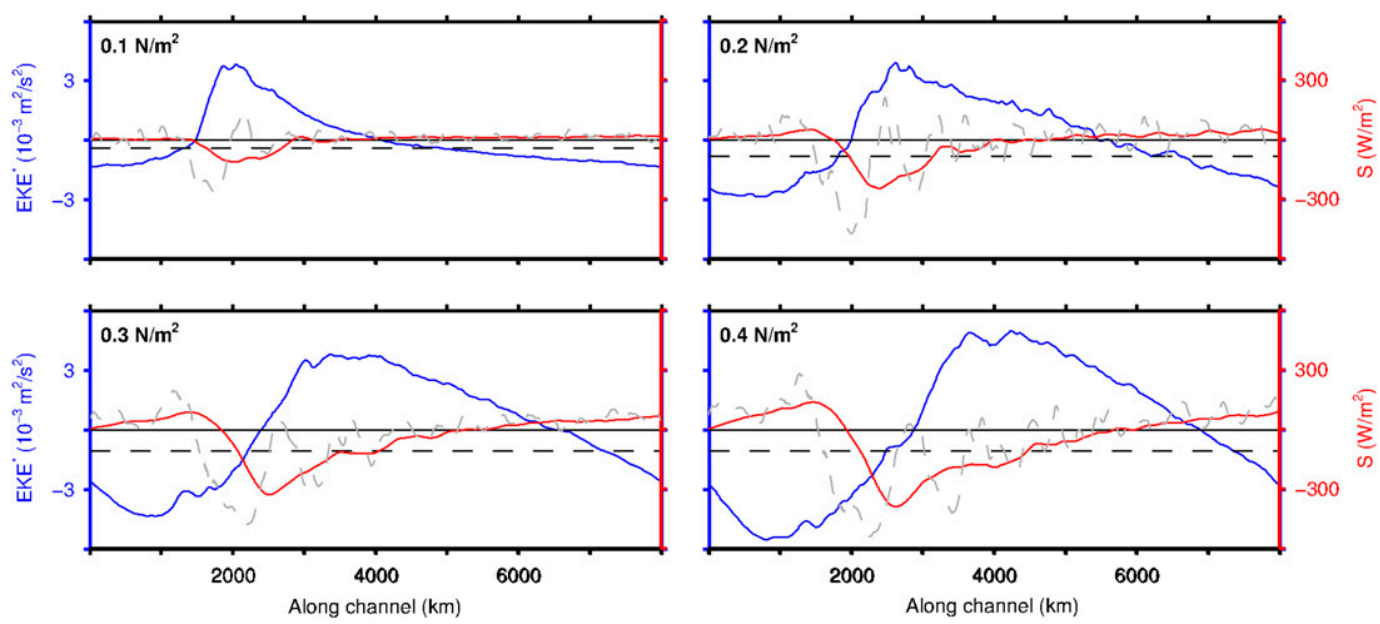

FIG. 3. Depth- and cross-channel-averaged EKE anomaly (difference from domain average, blue line) and $S$, defined in Eq. (8) (gray dashed line with red the 1000-km running mean), for different amplitudes of the wind stress. Storm tracks are defined by positive values of the blue curve. The black dashed line shows the difference in total EKE between simulations with and without topography for comparison.

line). It is much larger than the energy-containing length scale of transient eddies $O(100) \mathrm{km}$ and the Rossby radius of deformation $O(10) \mathrm{km}$. Similar to Kaspi and Schneider (2011a), we find that with increased wind stress amplitude, the meandering flow extends farther downstream along with the region where stationary eddy fluxes act to increase the isopycnal tilt $(S<0)$ and the region of anomalously high EKE. Somewhat surprisingly, EKE values downstream of the EKE maximum are actually suppressed in comparison to simulations without topography, consistent with a region where $S>0$.

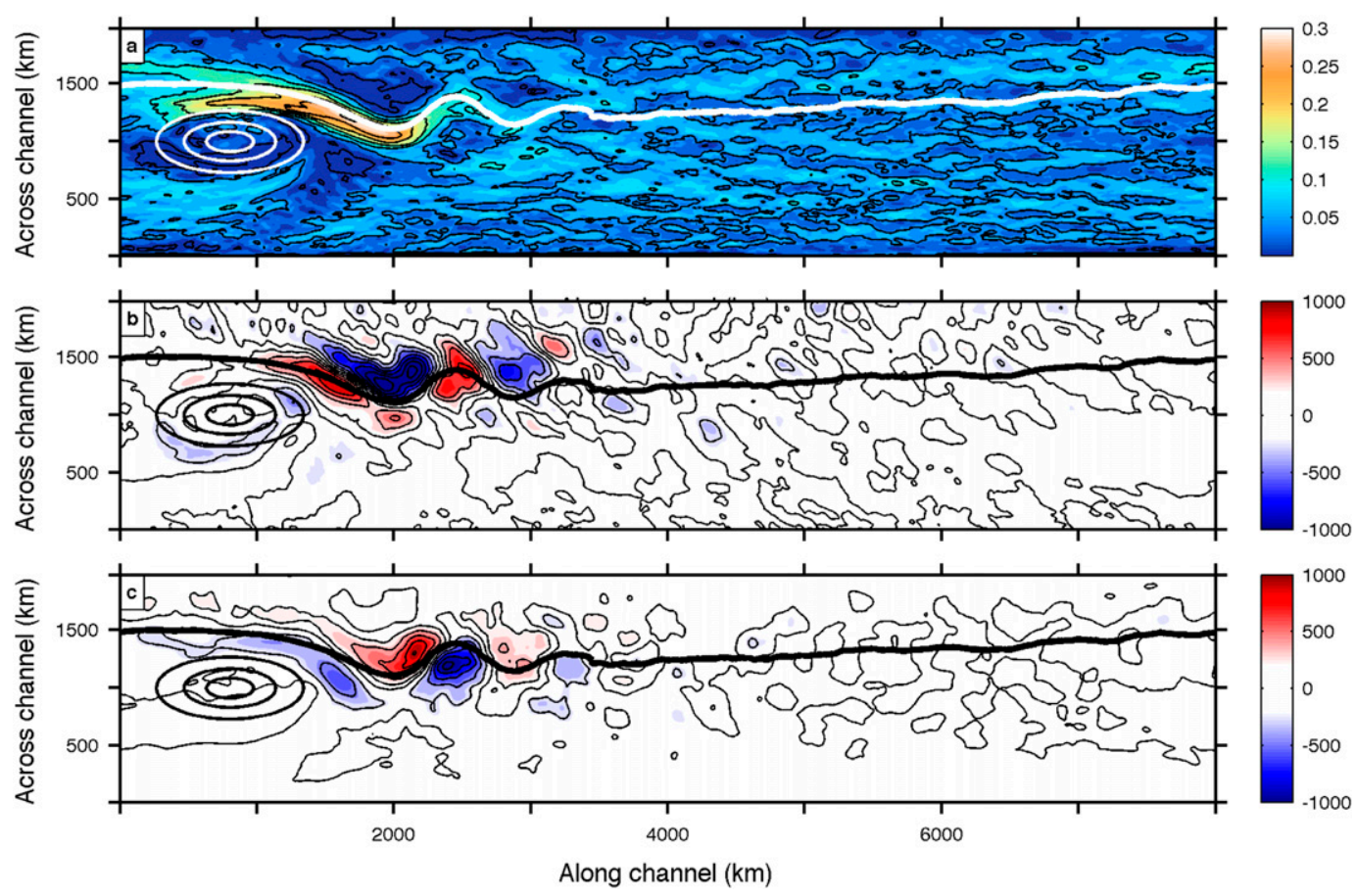

FIG. 4. (a) Above-sill average $(z<1.5 \mathrm{~km})$ of Eady growth rate $\left[\sigma=0.31 f\left(\partial_{z} u / N\right)\right.$, where $u$ is the zonal velocity field and $N$ is the buoyancy frequency] $\left(\right.$ day $^{-1}$ ) for wind stress amplitude $\tau_{0}=0.2 \mathrm{~N} \mathrm{~m}^{-2}$. (b), (c) Mass-weighted vertical integral of energy flux divergences $\left(\mathrm{W} \mathrm{m}^{-2}\right)$ for the $\tau_{0}=0.2 \mathrm{~N} \mathrm{~m}^{-2}$ simulation. (b) is $\boldsymbol{\nabla} \cdot\left\langle\rho c_{p} \overline{\mathbf{u}}^{\dagger} \bar{T}^{\dagger}\right\rangle$ and (c) is $\nabla \cdot\left\langle\rho c_{p} \overline{\mathbf{u}^{\prime} T^{\prime}}\right\rangle$. All fields are smoothed with a two-dimensional box filter of size $100 \mathrm{~km} \times 100 \mathrm{~km}$. 


\section{Discussion}

In our idealized setting, stationary eddy fluxes of heat (buoyancy) increase baroclinicity downstream of a simple Gaussian mountain. The location of strongest isopycnal tilting is not collocated with the maximum in EKE anomaly (Figs. 3, 4). While the bathymetric features are more complex in the ACC, stationary meanders are known to be sites of enhanced EKE. We also find that our results agree qualitatively with studies using ocean GCMs with more complex topography, for example, Thompson and Naveira Garabato (2014). Additionally, rapid transitions in eddy characteristics found in high-resolution ocean GCMs are consistent with the dynamics seen here.

Previous studies have suggested that stationary heat fluxes play an important role in shaping atmospheric storm tracks (Kaspi and Schneider 2011a,b). Our simulations show that the vertically averaged stationary heat fluxes are consistent with steeper isopycnals locally and that this steepening happens at length scales that are larger than the typical size of transient eddies (Figs. 2, $4 \mathrm{~b}, \mathrm{c})$. An intriguing result is that the dominant contribution to these anomalous upgradient heat fluxes by stationary eddies is associated with components that must integrate to zero along the entire channel. We note that an along-stream coordinate system will eliminate the stationary flux component. However, we argue that this change of coordinate system requires some a priori knowledge of the mean flow structure.

A key result of this study is that the structure of stationary meanders changes in response to an increased surface wind stress consistent with what is expected from eddy advection and local instability theory (Pierrehumbert 1984; Williams et al. 2007). Current views of Southern Ocean equilibration (e.g., Hogg et al. 2008) suggest that transient eddies compensate an increase in wind-driven Ekman overturning. Here, stationary fluxes respond to changes in meander size, which accompany a change in zonal-mean flow. This behavior is consistent with a modification in the standing Rossby wavelength (Hughes 2005). The associated change in EKE is localized in the stationary meander (Fig. 3) and is at least partly a consequence of the increased baroclinicity, although barotropic instability may be active as well (Tréguier et al. 2007). Thus, the eddy characteristics do not respond to a global change in stratification, but rather a local flux divergence. The distribution of this flux divergence and its release through baroclinic instability is also sensitive to the surface forcing and mean flow. Thus, to accurately study Southern Ocean storm tracks, or the interactions between mean flow, stationary meanders, and eddies of the ACC, not only is eddy-resolving temporal and spatial resolution required, but also a long domain that permits the system to adjust in a realistic manner. Since the topography of the ACC varies over a broad range of length scales, it will be important to consider the amplitude and distribution of stationary buoyancy fluxes with more realistic configurations.

The simulations presented here have an ACC transport that is too high to represent the real ACC because the channel is never fully blocked at depth at all latitudes. This leads to large bottom flow speeds. Although the barotropic component of the flow is larger than in nature and therefore the size of the standing meander might be unrealistically large in our simulations, the general principle of stationary heat fluxes tilting isopycnals remains valid in all our simulations, which span a wide range of surface wind stress forcings and mean flow amplitudes. Future process models should address the transient response of the channel stratification to a change in wind stress in a similar domain.

Acknowledgments. We thank Andrew Stewart and Andreas Klocker for comments on drafts of this paper and two anonymous reviewers for suggestions that improved its quality. This work was supported by NSF Grants OCE-1235488 and AGS-1019211.

\section{REFERENCES}

Abernathey, R., J. Marshall, and D. Ferreira, 2011: The dependence of Southern Ocean meridional overturning on wind stress. J. Phys. Oceanogr., 41, 2261-2278, doi:10.1175/ JPO-D-11-023.1.

Cai, M., S. Yang, H. Van den Dool, and V. Kousky, 2007: Dynamical implications of the orientation of atmospheric eddies: A local energetics perspective. Tellus, 59A, 127-140, doi:10.1111/j.1600-0870.2006.00213.x.

Chang, E. K., and I. Orlanski, 1993: On the dynamics of a storm track. J. Atmos. Sci., 50, 999-1015, doi:10.1175/ 1520-0469(1993)050<0999:OTDOAS > 2.0.CO;2.

Ferrari, R., and M. Nikurashin, 2010: Suppression of eddy diffusivity across jets in the Southern Ocean. J. Phys. Oceanogr., 40, 1501-1519, doi:10.1175/2010JPO4278.1.

Hallberg, R., and A. Gnanadesikan, 2001: An exploration of the role of transient eddies in determining the transport of a zonally reentrant current. J. Phys. Oceanogr., 31, 3312-3330, doi:10.1175/1520-0485(2001)031<3312:AEOTRO > 2.0.CO;2.

Hogg, A. M., M. P. Meredith, J. R. Blundell, and C. Wilson, 2008: Eddy heat flux in the Southern Ocean: Response to variable wind forcing. J. Climate, 21, 608-620, doi:10.1175/ 2007JCLI1925.1.

Hoskins, B., and P. Valdes, 1990: On the existence of stormtracks. J. Atmos. Sci., 47, 1854-1864, doi:10.1175/ 1520-0469(1990)047<1854:OTEOST>2.0.CO;2.

Hughes, C. W., 2005: Nonlinear vorticity balance of the Antarctic Circumpolar Current. J. Geophys. Res., 110, C11008, doi:10.1029/2004JC002753.

, and E. R. Ash, 2001: Eddy forcing of the mean flow in the Southern Ocean. J. Geophys. Res., 106, 2713-2722, doi:10.1029/2000JC900332. 
Kaspi, Y., and T. Schneider, 2011a: Downstream self-destruction of storm tracks. J. Atmos. Sci., 68, 2459-2464, doi:10.1175/JAS-D-10-05002.1. _ , and -2011 b: Winter cold of eastern continental boundaries induced by warm ocean waters. Nature, 471, 621-624, doi:10.1038/nature09924.

Lee, S., 1995: Localized storm tracks in the absence of local instability. J. Atmos. Sci., 52, 977-989, doi:10.1175/ 1520-0469(1995)052<0977:LSTITA > 2.0.CO;2.

Le Traon, P. Y., and R. Morrow, 2001: Ocean currents and eddies. Satellite Altimetry and Earth Sciences: A Handbook for Techniques and Applications, Academic Press, 171-210.

Lindzen, R. S., and B. Farrell, 1980: A simple approximate result for the maximum growth rate of baroclinic instabilities. J. Atmos. Sci., 37, 1648-1654, doi:10.1175/ 1520-0469(1980)037<1648:ASARFT>2.0.CO;2.

MacCready, P., and P. B. Rhines, 2001: Meridional transport across a zonal channel: Topographic localization. J. Phys. Oceanogr., 31, 1427-1439, doi:10.1175/1520-0485(2001)031<1427: MTAAZC $>2.0 . \mathrm{CO} ; 2$.

Marshall, J., and T. Radko, 2006: A model of the upper branch of the meridional overturning of the Southern Ocean. Prog. Oceanogr., 70, 331-345, doi:10.1016/j.pocean.2006.07.004.

— A. Adcroft, C. Hill, L. Perelman, and C. Heisey, 1997: A finite-volume, incompressible Navier Stokes model for studies of the ocean on parallel computers. J. Geophys. Res., 102, 5753-5766, doi:10.1029/96JC02775.

Naveira Garabato, A. C., D. Stevens, A. Watson, and W. Roether, 2007: Short-circuiting of the overturning circulation in the Antarctic Circumpolar Current. Nature, 447, 194-197, doi:10.1038/nature05832.

—, R. Ferrari, and K. L. Polzin, 2011: Eddy stirring in the Southern Ocean. J. Geophys. Res., 116, C09019, doi:10.1029/ $2010 J C 006818$.

Peixoto, J. P., and A. H. Oort, 1992: Physics of Climate. American Institute of Physics, $520 \mathrm{pp}$.
Pierrehumbert, R., 1984: Local and global baroclinic instability of zonally varying flow. J. Atmos. Sci., 41, 2141-2162, doi:10.1175/1520-0469(1984)041<2141:LAGBIO>2.0.CO;2.

Sokolov, S., and S. R. Rintoul, 2009: Circumpolar structure and distribution of the Antarctic Circumpolar Current fronts: 1. Mean circumpolar paths. J. Geophys. Res., 114, C11018, doi:10.1029/2008JC005108.

Swanson, K. L., P. J. Kushner, and I. M. Held, 1997: Dynamics of barotropic storm tracks. J. Atmos. Sci., 54, 791-810, doi:10.1175/1520-0469(1997)054<0791:DOBST>2.0.CO;2.

Tansley, C. E., and D. P. Marshall, 2001: On the dynamics of wind-driven circumpolar currents. J. Phys. Oceanogr., 31, 3258-3273, doi:10.1175/1520-0485(2001)031<3258:OTDOWD>2.0.CO;2.

Thompson, A. F., and J. B. Sallée, 2012: Jets and topography: Jet transitions and the impact on transport in the Antarctic Circumpolar Current. J. Phys. Oceanogr., 42, 956-972, doi:10.1175/JPO-D-11-0135.1.

— Antarctic Circumpolar Current by standing meanders. J. Phys. Oceanogr., 44, 1811-1828, doi:10.1175/JPO-D-13-0163.1.

_ , P. Haynes, C. Wilson, and K. Richards, 2010: Rapid Southern Ocean front transitions in an eddy-resolving ocean GCM. Geophys. Res. Lett., 37, L23602, doi:10.1029/ 2010 GL045386.

Thompson, D. W., and S. Solomon, 2002: Interpretation of recent Southern Hemisphere climate change. Science, 296, 895-899, doi:10.1126/science.1069270.

Tréguier, A. M., M. England, S. R. Rintoul, G. Madec, J. Le Sommer, and J.-M. Molines, 2007: Southern Ocean overturning across streamlines in an eddying simulation of the Antarctic Circumpolar Current. Ocean Sci. Discuss., 4, 653698, doi:10.5194/osd-4-653-2007.

Williams, R., C. Wilson, and C. Hughes, 2007: Ocean and atmosphere storm tracks: The role of eddy vorticity forcing. J. Phys. Oceanogr., 37, 2267-2289, doi:10.1175/JPO3120.1. 